\title{
BRANDING GENDER IN CLIMATE CHANGE ADAPTATION POLICIES IN BANGLADESH
}

\author{
Sadia Binte Rezaq
}

\begin{abstract}
Purpose :

The climate change issues in Bangladesh are not new. However, the integration of gender-sensitive perspective in climate change research is a recent phenomenon. Very few researches have considered the linkage between climate change and gender. For this reason, this research paper seeks to make the most of the accessible resources, strengthen future researches and interventions on gender and climate change policies and adaptation planning. By illustrating existing publicly available literatures and personal communications with experts in the field of gender and climate change, the paper will highlight the challenges of mainstreaming gender into climate change adaptation programs and of making gender more central to all policy development.
\end{abstract}

The research has been divided into three thematic areas, which are interlinked: climate change impacts and their gender implications, the hazard-specific impacts of climate change, current adaptation strategies and future viable livelihood options.

\section{Methodology:}

The study areas have been divided into three different hazard-prone zones: cyclone-prone coastal areas, drought-prone areas and flood-prone areas. Considering the time and budget constraint for conducting the study and based on the risk assessment, the most risky and highly vulnerable areas will be selected as the sample study areas.

\section{Findings:}

The impact of climate change in the selected study is identified through KII and FGD.KII was conducted with the UNO, DC and other community member. Contribution from the existing published literature on the impact of climate change on gender was also being taken. Current adaptive practices exercised by the local people, the role of gender will be identified also through FGD and KII. KII was performed with the UNO, DC and other community member. In addition, field level adaptive practices with the government policies was also identified. Before that, to what extent government includes the gender-based adaptive techniques will be identified. Extent of utilization of IPCC recommended adaptive techniques was also being examined.

\section{Value of the research}

The research covers the grass root level communities in the distinct characterized zone of Bangladesh which is: Coastal area, drought-prone and flood prone areas. This paper gives a clearer understanding of the social, economic and cultural reasons behind particular impacts and to identify solutions that will benefit women and men along with elderly people and children experiencing these impacts

Keywords: Women, gender, vulnerability, climate change, sustainable development 


\section{Background of the study}

Bangladesh is one of the many parts of the world where the impact of climate change is visible and widespread. Due to the geographical location and the topological features of the country, it is exposed to almost all kinds of natural disasters each year. Approaches to respond to weather-related hazards differ between women and men; women tend to have much lower access to critical information on weather alerts in Bangladesh. Thus, affects their capacity to respond effectively to climate variability. The changing climate has some direct impact on economic activities like crop yield loss, demolished homes, and food insecurity (IPCC, 2014).The rampant effects of climate-induced disasters, however, fall disproportionately on particular poor men and women who have no capacity to possess alternative resilient livelihood resources for effective disaster-related preparedness and recovery.

The climate change issues in Bangladesh are not new. However, the integration of gender-sensitive perspective in climate change research is a recent phenomenon. This study seeks to make the most of the accessible resources, strengthen future researches and interventions on gender and climate change policies and adaptation planning. By illustrating existing publicly available literatures and personal communications with experts in the field of gender and climate change, the paper will highlight the challenges of mainstreaming gender into climate change adaptation programs and of making gender more central to all policy development.

\section{Objective}

Considering the climate determinants of Bangladesh, the study assesses gender vulnerabilities in Bangladesh. The General objective of the study is to find out the effects of climate change on different gender perspectives and reduce the disparities of gender role on climate change adaptation.

\section{Scope of the study}

The scopes of the paper are-

- Understand the vulnerability due to climate change focused on gender or vulnerable group

- Identify the impacts of climatic events in the selected study area

- Assessment of the role of gender in climate change adaptation

- Proposed equitable future adaptation strategies to reduce the disparities of gender.

\section{Understanding the context}

\section{The notion of Gender}

There is a widespread confusion about what is meant by the term 'gender', as it has been conceptualized differently in research areas.

\section{According to WHO,}

"Gender refers to the socially constructed norms, roles and relations that a given society considers appropriate for men and women".

World Development Report defines Gender to socially constructed and learned female and male roles, behaviors, and expectations. According to the report, all cultures interpret and translate the biological differences between men and women in beliefs about what behaviors and activities are appropriate for each gender as well as their rights, resources, and power. For example, most societies are given the primary 
responsibility for the care of infants and young children to women and girls, and that for military service and national security to men. Gender thus shapes one's life chances and one's role in the home, in society, and in the economy (World Bank, 2000).

In the context of the FAO, Gender is a central organizing factor in societies, and it can significantly affect the processes of production, consumption and distribution. In fact, the influence of gender on rural people's lives and livelihoods is so substantial that "by any indicator of human development, female power and resources are lowest in rural areas of the developing world. Notwithstanding recent improvements in their status, they have the world's lowest levels of schooling and the highest rates of illiteracy. It defined Gender as not to male and female, but to masculine and feminine - that is, to qualities or characteristics that society ascribes to each sex. People are born female or male, but learn to be women and men. Perceptions of gender are deeply rooted, vary widely both within and between cultures, and change over time. But in all cultures, gender determines power and resources for females and males (FAO, 2011).

Social and economic inequalities between men and women undermine food security and hold back economic growth and advances in agriculture (FAO, 2011a).In all developing regions, female headed rural households are among the poorest of the poor"(FAO, 2011b).

"The Intergovernmental Panel on Climate Change (IPCC) Fourth Assessment Report (IPCC, 2007) discusses the differential impact of climate change on men and women. The physical, psychological, social and economic impacts they experience together with the emergency responses, recovery and ultimately reconstruction are different."

It is apparent from the statement that The IPCC, 2007 does not emphasize the impacts of climate change on children, older and physically disabled person from the perspective of gender equity.

From the above review of literature, it can be stated that, the general emphasis focuses on women as a gender. This study will focus on a more thorough analysis of climate change impacts on gender, so that responses can be tailored to the specific needs of all levels. It is already mentioned in various studies that, women are likely to be affected more by the impacts of climate change. In times of stress, especially girls and elderly people are often the most vulnerable. According to a report by UNICEF, children are particularly susceptible to disaster-related and health impacts of climate change, including an increased prevalence of malaria, diarrhea and under-nutrition. In addition, older people are also particularly vulnerable to the effects of climate change. To identify the gender disparity, children, old age people are included with other social group in this study. According to IPCC 2007, climate change will certainly exact the heaviest toll among those socioeconomically disadvantaged, the poor, the very young, and the old. However, they are excluded from the gender dimensions. The study will embrace this particular group of people (women, children and old age people) as are repositories of indigenous knowledge and experience that could contribute to local and national adaptation. In-so-doing, this study will particularly concentrate to the heterogeneous group and identify how these groups are affected by overall climate change context.

\section{Gender Dimensions of Climate Change, Vulnerability, and Adaptation}

Bangladesh is one of the countries that are most susceptible to sea level rise and other climate change vulnerabilities. This situation is exacerbated by its developing country status with high population and vulnerable geophysical location. Bangladesh experiences frequent severe weather disasters like floods, cyclones, heavy rains, droughts, river erosion and salinity intrusion. These disasters have increased in both frequency and intensity. This is affecting traditional lifestyle and livelihoods, especially if their livelihood is dependent on agriculture (Ahmad, 2010).

Gender is slowly taking its position as an important aspect of climate change. COP 16 in 2010 acknowledged that climate change effect will be felt most severely by vulnerable population owing to geography, gender, 
age, indigenous or minority status and disability. It states that that a country-driven, gender-sensitive, participatory and fully transparent approach should be followed in adaptation action (UNFCCC 2010: 1-3).

A gender analysis recognizes that men and women play different roles in their families, communities and societies; they also have different kinds of access to information, resources and networks. It assesses the impact that an activity may have on men and women, and on gender relations (Hunt, 2004).

The Intergovernmental Panel on Climate Change (IPCC) Fourth Assessment Report (IPCC, 2007) confers the differential impact of climate change on men and women. IPCC report also stated that the physical, psychological, social and economic impacts they experience together with the emergency responses, recovery and ultimately reconstruction are different. They have the least capacity or opportunity to prepare themselves for the impacts of climate change. In addition, the report recognizes that women play an important role in disaster reduction, often informally, through participating in disaster management and acting as agents of social change (IPCC, 2007). Globally there has been a limited research on the linkages between adaptation to climate change and gender. Despite of the fact that gender plays a role in determining a person's vulnerability to climate change, much of the research and discourse on climate change adaptation has focused on the scientific, technical and infrastructural aspects of addressing the challenge.

The United Nations Framework Convention on Climate Change (UNFCCC) Conference of the Parties (COP) has been criticized by gender experts in not addressing gender in negotiations or of only paying it lip service (Röhr, 2006; Hemmati, 2008; WEDO, 2010) to address in the sustainable development goals.

Gender is one of the most important determinants in climate change mitigation and adaptation. However, gender aspect of climate change is a buzz word where women are considered as more vulnerable. But many studies show that, women have been instrumental in organizing themselves and others in the context of sustainable development and environmental issues (Dankelman, 2002). Therefore, long term monitoring and research are needed to have a full understanding of the dimensions of gender.

\section{Physical context of the study sites}

The following map and table (Annex) highlights the study areas chosen for this study 

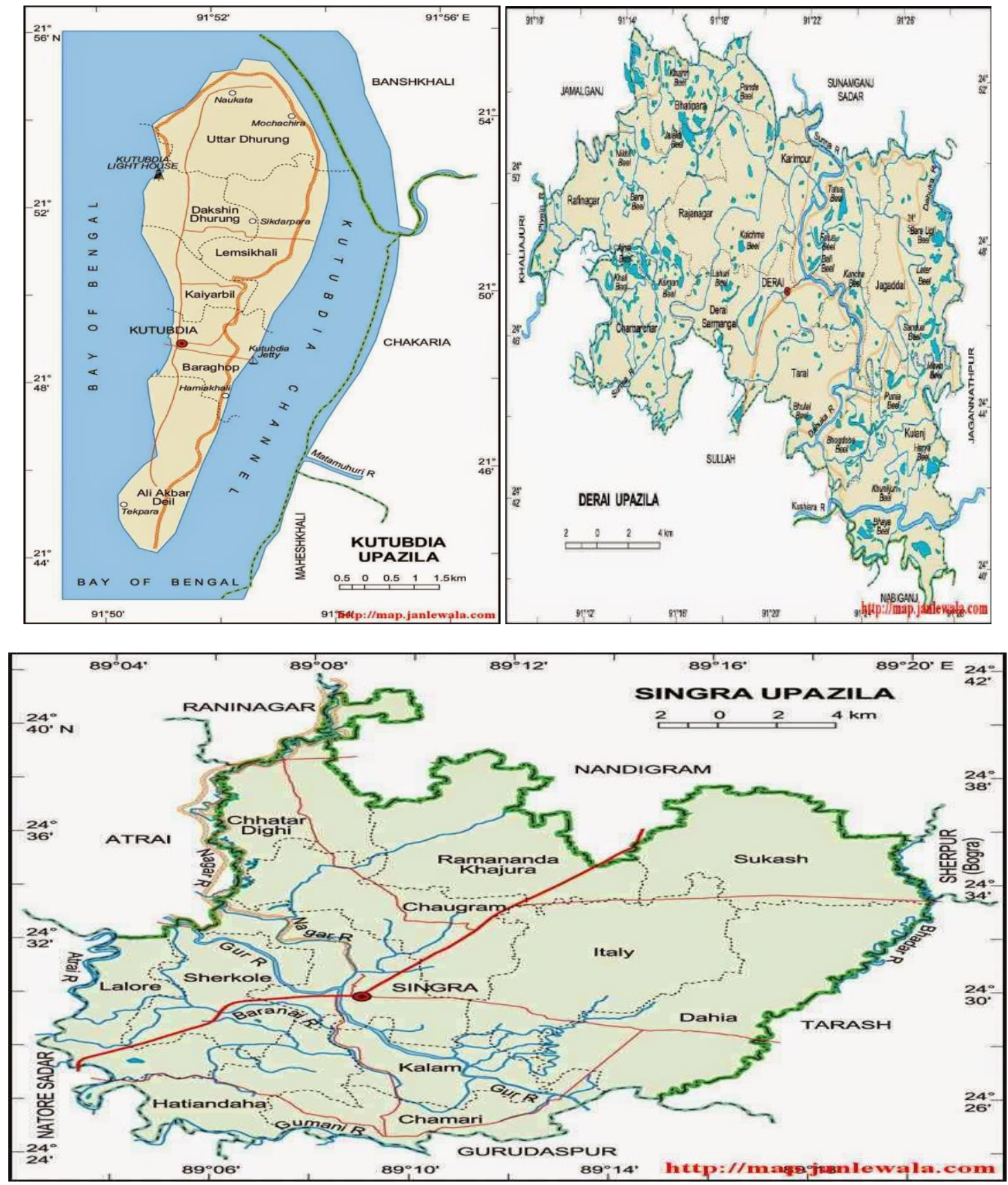

Table 1 Demographic Information of the Study Areas

\begin{tabular}{|c|c|c|c|c|c|c|c|c|c|c|c|c|c|}
\hline \multirow[t]{2}{*}{ District } & \multirow[t]{2}{*}{ Upazila } & \multirow[t]{2}{*}{$\mathrm{HH}$} & \multicolumn{3}{|c|}{ Population } & \multirow{2}{*}{$\begin{array}{l}\text { Sex } \\
\text { Ratio }\end{array}$} & \multicolumn{3}{|c|}{ Age Distribution (\%) } & \multicolumn{3}{|c|}{ Literacy Rate (\%) } & \multirow[t]{2}{*}{ Hazards } \\
\hline & & & M & $\mathrm{F}$ & Total & & $\begin{array}{l}\text { Below } \\
15\end{array}$ & $\begin{array}{l}15- \\
59\end{array}$ & $\begin{array}{l}\text { Above } \\
60\end{array}$ & $M$ & $\mathrm{~F}$ & Tota & \\
\hline $\begin{array}{l}\text { Cox's } \\
\text { Bazar }\end{array}$ & Kutubdia & 22587 & 64093 & 61186 & 125279 & 105 & 44.1 & 50.1 & 5.7 & 34.8 & 33.2 & 34.0 & Cyclone \\
\hline Sunamgonj & Dhirai & 45040 & 122636 & 121054 & 243690 & 101 & 40.5 & 51 & 8.4 & 38.5 & 35.8 & 30.4 & Flood \\
\hline Nator & Singra & 88791 & 182586 & 181796 & 364382 & 100 & 31.8 & 60.5 & 7.7 & 46.3 & 39.6 & 42.9 & Drought \\
\hline
\end{tabular}




\section{Gender Specific Impact Analysis of Common Natural Hazards}

Various climate change induced disasters such as prolonged flooding, drought, cyclones, tornadoes and erratic rainfall result in loss of lives and livelihoods of many, especially the old, women and children, devastation of human settlements and infrastructure, loss of agricultural land and fisheries, employment opportunities, health-related risks and so on. However, most climate change issues, policies, and programs are not gender neutral (CCC, 2009).

Economic disadvantages, depending on men, the discrimination towards the access to and control over productive resources, and limited decision-making power make women more vulnerable to climate change induced problems. Hence, the effects of climate change are likely to affect men and women differently. In addition, higher rates of illiteracy among women and girls, and lack of access to information on climate change also exacerbate the situation.

When a hazard strikes, it is women who have to safeguard all the belongings and assets, send everybody to safer refuge, and stay back to ensure that the household is not ransacked while in the absence. Sometimes, such an apparent 'passive' response may lead to death and such kind of risk is deliberately undertaken by women (CCC, 2009). Women are usually paid less than men in terms of physical labor and are also sexually harassed in the absence of their male counterpart. Several studies have also indicated that women are more vulnerable than men, both to short-term climatic events (major natural disasters) and long-term climateinduced changes (sea level rise, salinity intrusion in water and soil, land erosion, drought), because they magnify existing social and gender inequalities (Ahmad N. , 2012).

There is some evidence that reveals that following a disaster, the possibility of women and girls suffering from domestic and sexual violence increases. This situation prevails, especially when families displace and stay in the temporary emergency shelter where they lack privacy. Although women have less financial ability and decision-making power than men, they have to bear the burden of meeting the needs of the family while fighting natural adversities as being the sole household manager.

Women's Vulnerability To Climate Change

\section{Impact of climate change induced hazards on Women}

The study indicated that, dissemination of warning information was done by men to men in public places, but seldom communicated to the rest of the family. A large number of women were not allowed to leave the house without a male relative. In such context, they had to wait for their relatives to return home and take them to a safe place.

Access to information is gendered. Women have confessed that men, on receiving the warning first, sometimes do not transfer the information to their respective family members. As a result women are usually unaware of the climatic hazards and even if they become aware, they cannot quickly reach the cyclone shelters since they are ones who have to take care of their families before they leave. Sometimes women are unwilling to go to the cyclone shelters due to 'insecure' environment over there and instead, they prefer to stay back during the storm.

Health Impacts are also gendered. Epidemics, waterborne diseases, snakebites, drowning, injuries occur from large trees and structures falling on women, lack of medical facilities, malnutrition, lack of pure drinking water and lack of proper sanitation diseases causes death, injuries and diseases to women during disasters. It has been already reported that, as the sanitation systems are ruined, many adolescents and women desist from using the toilet during the day and as a consequence they suffer fron UTIs (urinary tract infections). The worst 
sufferers are the pregnant women, lactating mothers and differently disabled women (Dankelman, Alam, Ahmed, Gueye, Fatema, \& Mensah-Kutin, 2008).

It was found out that, in the coastal areas, tidal surge and storm are identified as the most damaging hazards, followed by saline water intrusion. Death and destruction of dwellings and food insecurity occur as a consequence of such vulnerability. Fresh drinking water is not accessible as during hazard period, tube wells are often damage. In such context, women have to fetch water from long distances that lead them towards a vulnerable living condition in the post phases of cyclone hazard.

Often women are harassed sexually during the disaster and post disaster period. After the incident of 1991 cyclone, it was reported that young women were abducted and abused, and it has also been documented that there has been harassment in shelters, especially where there is not a separate safe space for women to toilet, shower and sleep (UN Women Bangladesh, 2014).

For elderly and pregnant women, the situation becomes more aggravated when vehicles are often unavailable to go to the nearest cyclone shelter. Consequently, the situation becomes more difficult for them, when they have to walk along muddy rural roads under stormy conditions. On the other hand, almost no cyclone shelter has a ramp to carry the disabled persons and pregnant women safely. In some areas, where cyclone shelter is inaccessible, women spend days in an unsafe condition in the nearby embankment.

\section{Impacts of Drought on Women}

In the disaster period, it is usually the woman who upholds the responsibility of the entire family and all the household works. Hence, they are the ones who suffer the most in any disaster. According to the FGD findings of Naogaon district in (CCC, 2009), the problem of access to safe drinking water becomes evident during this drought condition. Sanitation facilities again are hampered due to the unavailability of water. As a consequence, the outbreak of diseases like diarrhea, cholera, and dysentery is inevitable. Also, if a household desperately wants to keep the livestock, the woman is again forced to 'manage' water for the animal. It is often a family decision (i.e., the decision of the male within the family) which the woman can only obey.

\section{Impacts of flood on Women}

Riverine flood, flash flood, coastal flood, and urban flood adversely affect the people (especially the aged, women, children and the special care needed persons) in various ways. Flood related deaths caused by drowning and snake bites, tend to occur in increasing numbers for children, following by adult women (CCC, 2009).

The frequent occurrence of flash floods poses a severe threat to lives, livelihoods, costly infrastructure. The hardest hit are the socially most vulnerable, the poor, women and children, who can just locate their destination to survive in floodplains or other sensitive areas (CCC, 2009). People suffer more in the flash flood than in the regular flood due to its unpredictability. It has been observed that women are vulnerable in a different way in events like flash flood. For instance, flash flood often washes away latrines of the family making it difficult for women to survive. They face sanitation problem also in the places where they take shelter, especially if it is an embankment. Preservation of fuel is necessarily a significant responsibility of women that become difficult during the aftermath of an event. Also, flash flood floods out the primary sources of income for many rural women in Bangladesh poultry, livestock, etc. Most of the time, the middle aged or teenager girls catch fish at night or very early in the morning to avoid deprecating responses from the society. The reason behind this is, in rural areas, women's work outside home in front of strangers is unacceptable from a religious point of view. 


\section{Impacts on Men}

Men in the cyclone-prone areas of Bangladesh live on fishing. They travel to the deep sea to prey fish and are often preyed by the storm / cyclone. Because of lack of knowledge they hardly take any precaution and so it becomes very difficult for them to escape death. As per our social norm, women, old and children are more vulnerable and are thus rescued first for which men are negatively affected. For instance, because of lack of space in the shelter, the weak people get preference as a result men are left unattended in the open space during storm/cyclone. Besides, during flood and drought, male farmers lost their crops and suffered through financial burden.

In the post-disaster event, the financial burden of the family usually falls upon men. As a result, they have to migrate to the suburbs/cities in search of job, leaving their families behind and are thus impacted physically and psychologically. However, some of them do not return, leaving the sole responsibility of the family upon the women. However, many climate change responses and institutions are gender-biased, providing privileges to men in the distribution of their needs, opportunities and resources.

Children, elderly persons and people those need special care are also affected by the impacts of climate change induced hazards. The female children and elderly women are more vulnerable in particular than male children and elderly men.

\section{Impacts on Children}

Children are more vulnerable to the impact of climate change than adults because they are more susceptible to various diseases such as waterborne diseases, malaria, cholera, acute risk of malnutrition and so on which have long-term development implications for the children. As a result of climate change, waterborne diseases and diarrhea are expected to increase. Because children have greater contact with water than adults (due to playing outside), they have a greater intensity of diseases. A study in Bangladesh found that the number of non-cholera, diarrhea cases per week increased by 5.1 percent for every $10 \mathrm{~mm}$ increase above the threshold of $52 \mathrm{~mm}$ of average rainfall. 3.9 percent also increases the number of instances for every $10 \mathrm{~mm}$ decrease below the same threshold of precipitation (Masahiro, H. et al., 2007). Children in developing countries suffer a number the environment linked diseases like malaria and cholera, increased the likelihood of food and water shortages, and disruption to their education due to the effect of climate change. It is estimated that more than 88 percent of the existing global burden of disease due to climate change impacts occurs in children under the age of five (WHO, 2012).

Risk of girls are more than boys since they stay at home when a flood hits and are less liable to know how to swim than their brothers, but both girls and boys are at higher risk than adults. This study further showed that children aged two to nine were twice as likely to die as their same-sex parent (Pradhan, West, Katz, LeClerq, Khatry, \& Shrestha, 2007).According to UNICEF (2008), girls are at greater risk due to climate change than the boys. The girls are asked to assist their mothers in tasks such as collecting firewood and water, as a result of which they have to escape schooling. Moreover, migration followed drought, severe flooding and other natural disasters has grave consequences for children.

In Bangladesh, children aged less than five years old are most at risk due to climate change. It has been found that, child death after the natural disaster has increased and they died mainly from diarrhea, Pneumonia, and injury-related causes. One of the major impacts is they frequently miss school, which results in dropouts. Lack of transportation service is one of the reasons for these dropouts. During early flash floods, children are forced to get involved with agricultural activities such as quick harvest of paddy by their parents. When families or male heads of the families migrate in search of employment to other places, children often engage in economic activities. Due to improper sanitation practices and lack of awareness, the majority of the children suffer from water borne diseases. 


\section{Impacts of on elderly persons}

The mental vulnerabilities of the older people are more than their physical vulnerabilities. The elderly people are already exposed to various health related problems and the effects of climate change overload their burden.

In Bangladesh, aftermath of Sidr, many elderly people are now suffering from eyesight problem, back pain, virus fever, and physical weakness. Diseases such as dysentery, skin disease, jaundice, common fever, cough $\&$ cold and typhoid were regular features in the Sidr affected areas. Many elderly people died as a result of injuries sustained by being hit by falling trees and houses collapsing.

\section{Impacts on persons those require special care/ differently able people}

Although very limited researches have been conducted on the impact of climate change on the disabled person, but in times of disaster, the visual, hearing and speech impaired person faces a number of difficulties to escape or reach the shelter on time. When other members of their families move on, they are often left behind in a degraded environment. Persons with disabilities are additionally vulnerable since they are unable to move to safety location and also they may be invisible to relief workers, who are unaware of their particular vulnerabilities.

Women, men and children with disabilities are often excluded from aspects of a community's daily life because of a lack of awareness or assumptions made by other members of that community (Turnbull, Marilise; Sterrett, Charlotte L.; Hilleboe, Amy, 2013).

Physical disability often gets associated with severe psychological and physical trauma that makes them difficult to cope with climate change impact. Some people in the rural areas consider mentally disable person as "crazy" people and thus are not paid attention to or assisted by others. The situation is worse for the disabled people because information or knowledge gap exists between the needs of people with disabilities. Many cyclone shelters do not have the necessary facilities such as the ramp, wheelchair, assistive medical equipment or accessible toilets for the disable people. Again the majority of the disabled people are living below the poverty line having inadequate access to many goods and services required to adapt to climate change scenarios, which further increases their vulnerabilities.

In Bangladesh, they are often treated with disregard; hence they are the most vulnerable of the society. During a natural disaster, problems experienced by disabled people on daily basis are magnified and exacerbated their situation. Differently able people are often left in the house as there is no sufficient space for them in the cyclone shelters. In the time of disaster, they solely depend on women. Thus, it becomes difficult for women to leave the house and move on to the shelter.

Climate change induced Vulnerabilities of people requires special treatment

- Lack of accessibility in evacuation

- Lack of response, and recovery efforts

- Exclusion of disability issues in planning and preparedness

- Lack of awareness 


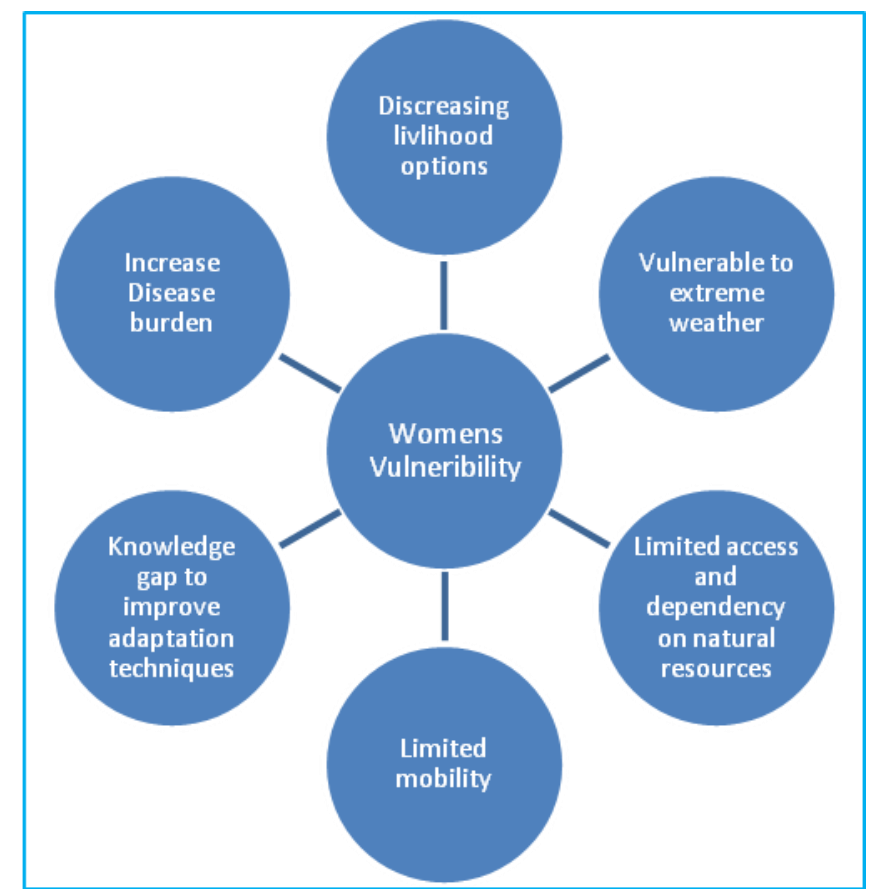

\section{Identification of the role of Governance}

"Disasters don’t discriminate, but people do" (UNISDR, 2009)

\section{Main Actors in Climate Change Governance}

There are a range of actors addressing issues related to climate change. Each actor is making unique contribution in their own capacity which represents a somewhat encouraging scenario. While government is playing the central role in policy formulating and implementation, many private organizations have also been trying to implement programs based on their experience and priorities. Climate change governance requires a multi-sectoral response. Hence, relevant governance policies and actors involved with climate change, adaptation, poverty, health, gender and vulnerability are to be reviewed. This paper identifies the following as the relevant actors in the field of climate change (Figure 1).

- National and local government

- Development partners and International Financial Institutions

- $\mathrm{CSO}$ 's

- Academic and research institutions

- Private sector

- Media 


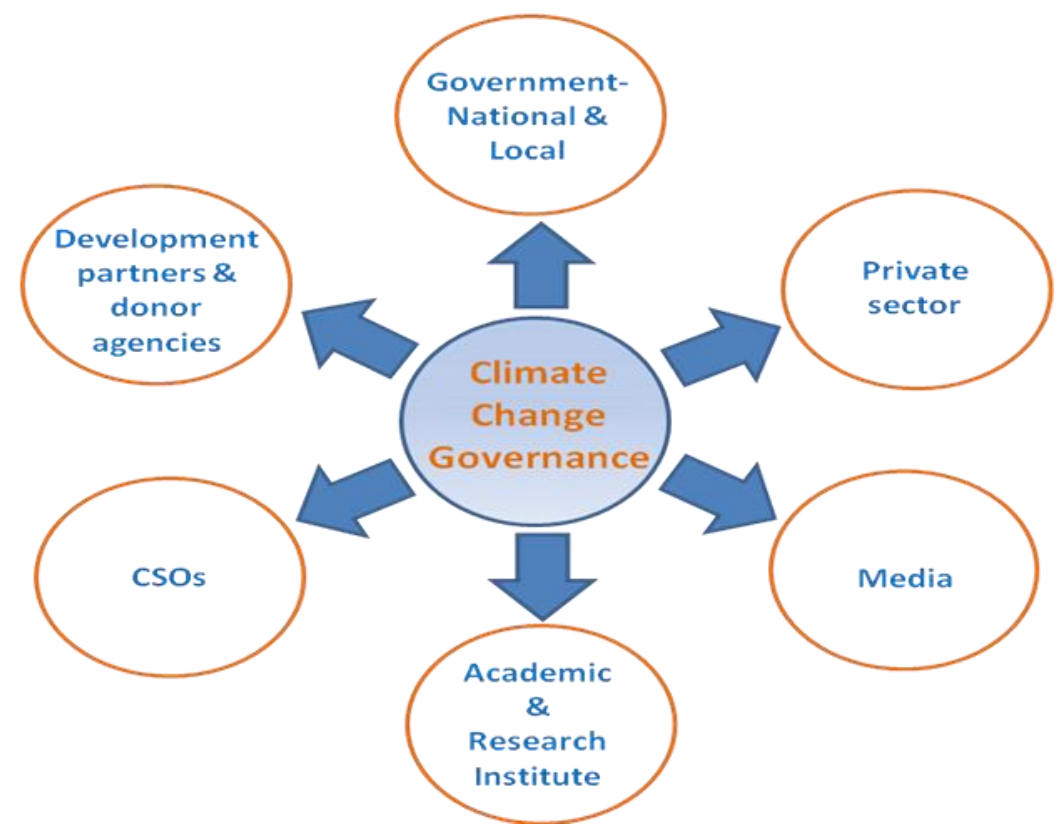

Figure 1. Main actors of climate change governance

\section{National and Local Government}

Bangladesh is one of the accomplice countries to UNFCCC and the Kyoto Protocol. A 'Climate Change Cell' has been created in the Department of Environment. The objective of creating the cell was to prepare and adopt a coordinated strategy regarding issues related to climate change at local and national levels. The cell has been working under the support of the Comprehensive Disaster Management Programme (CDMP) of the Ministry of Food and Disaster Management.

A National Adaptation Programme of Action (NAPA) was prepared in 2005 by the Ministry of Environment and Forest (MOEF) in response to the decision of the Seventh Session of Conference of the parties of the UNFCCC. In NAPA, six sectoral working groups were established, one of which was the 'livelihood, gender and local governance and food security' group coordinated by the Bangladesh Institute of Development Studies. Although it is important for women to be present in all discussions and for genderbased issues to be considered under the six established working group activities, it is unclear if women's groups or gender-based issues were considered in deliberations.

Local government institutions (LGIs) have a direct connection and clear understanding of the needs of local people. The representatives being elected through direct votes from the local population act as the first point of contact for most of the issues affecting the community members' lives and livelihoods. LGIs have been partnering with NGOs and donors to implement climate change initiatives. However, women representatives in local government are often neglected and therefore cannot contribute much in gender specific issues.

\section{Development Partners and International Financing Institutions}

Undoubtedly, development organizations and international financing partners have contributed significantly in advancing the programs and projects connecting gender and climate change. Some of these organizations acted as pioneers in introducing the idea of gender specific issues related to climate change. The Commonwealth Centre, the Dutch Ministry of Public Works, the Asian Development Bank (ADB), and the Ford Foundation did some early financing to develop the initial knowledge-base on specific vulnerabilities to climate change. Eventually, the United States Agency for International Development (USAID) and the World Bank provided grants for conducting more in-depth studies. 


\section{Civil Society Organizations}

The communal strength of CSOs strengthened Bangladesh's capacity to address social issues more than in other least developed countries. NGOs have contributed significantly in:

- Raising awareness of basic concepts causes and risks of climate change and possible ways to address these issues;

- Advocacy, campaigning, and research on early responses to climate change;

- Piloting community-based adaptation (CBA), as well as media advocacy, and campaigning on CBA;

Several NGOs have contributed significantly through their programs aimed to reduce gender specific vulnerabilities in disaster prone areas.

\section{Academic and Research Institutes}

Recently, a large number of public and private universities have included climate change courses and some of them have set up separate centers (e.g. International Centre for Climate Change and Development-ICCAD Centre for Climate Change and Environmental Research-C3ER), Bangladesh Centre for Advanced Studies for climate change research. In addition to substantial amount of research works, these organizations also implement climate change adaptation and disaster risk reduction programs and initiatives.

These organizations are contributing to enhance the knowledge base through a significant amount of primary and secondary research on climate change induced vulnerabilities and responding policy and governance mechanism.

\section{Media}

A number of media organizations now have specialized reporters who received training prior to the Copenhagen Climate Change Summit in 2009. The main contributions of media are as followed:

- Raising awareness through news coverage, special reports, and seminars;

- Featuring best practices in community based adaptation;

- Coverage of international negotiations and other major environmental summits and conferences;

- Documentation of major environmental disasters in digital media; and

However, the national media coverage of the issues related to climate change is not gender sensitive. Gender based vulnerability is featured in a limited scope. Absence of intense research sometimes lead to wrong interpretation of certain matters related to climate change. Also, women are generally featured as vulnerable not as active participants in the adaptation and mitigation process.

\section{Private Sector}

The private sector is yet to go a long way to implement initiatives to prepare for future climate induced hazards. Poor communication and limited knowledge sharing among the research community, the government and the private sector on climate change related issues are to blame for their limited involvement. 


\section{Multi-Sectoral National Policies \& their Gender Sensitivity}

It is now well established that while communities and regions may be exposed to similar adverse effects of changing climate, the degree of their vulnerability to those changes vary greatly. The contemporary literature on climate change now acknowledges, the patterns of vulnerability to climate change impacts are shaped by social factors ranging from gender roles to a class to ethnicity. This is because; these social factors shape access to livelihood resources and roles in decision making. In short, these social factors have broad ramifications for the ways in which people experience and address the impacts of climate variability and change in their lives. Limited access to resources and to decision-making processes, mobility places women in rural areas in a position where they are disproportionately affected by climate change. It is thus important to identify gender-sensitive policies to respond to the environmental and humanitarian crises induced by climate change.

Currently two dominant viewpoints are observed in the field of gender and climate change. One depicts women as victims, being disproportionately impacted by climate change. The other viewpoint focuses on the role women play in climate change governance featuring women as being more resilient and having more agencies in these contexts. It is important to remember that women are not only the victims of climate change but they are also effective actors or agents of change in relation to both mitigation and adaptation.

Women often have sound knowledge and expertise which can be used in climate change adaptation and mitigation as well as disaster reduction. Furthermore, women being the stewards of natural and household resources can contribute to adaptation strategies in changing environmental realities. Therefore, when it comes to decision-making and implementation towards building resilient communities in the face of climate change, the full and meaningful participation of women become essential. To ensure such participation, climate change policy needs to be gender sensitive because if climate change policy fails to take into account the interests of all stakeholders, it cannot lead to a sustainable future.

The government of Bangladesh recognizes the need for coordinated

The key indicators of gender sensitivity:

- How did the project or policy work benefit women and men differently?

- To what extent were the different vulnerabilities and capacities of women and men taken into account?

- Did the project or policy work enhance gender equality and women's empowerment, or work against it? In what ways?

- Is the project having positive or negative effects on gender relations?

efforts on gender issues and the need to mainstream gender issues in development initiatives to increase resilience. At present Bangladesh is engaged in aligning national legislation and policies with its international commitments to strengthen gender dimensions. Some key policies are with regards to climate change and adaptation and the provision of gender issues in those policies are highlighted below. In addition, there is also a set of supporting 'Rules' and 'Regulations' that include important provisions. For example, the Social Forestry (amendment) Rules (2009 and 2011) present forestry programmes for women to benefit through receiving a share of the proceeds from selling harvested lots. 


\section{Gap Analysis}

The vulnerabilities as well as needs of women are far from being mainstreamed into climate change policies and operational activity in Bangladesh. Most of the policies are reactive in nature. Lack of effective proactive policies is another major weakness. Some experts have noted that policy objectives related to climate change and gender are generally addressed as mutually exclusive issues and existing policies do not consider gender-specific operational activities. The only policy that includes gender-based considerations for climate adaptation is the Poverty Reduction Strategy paper (2005), however operational activities under this policy have not yet fulfilled these objectives.

While policies may acknowledge the particular vulnerabilities of women, but do not necessarily have any operational planning to address the vulnerabilities. Furthermore, Shabib and Khan (2014) noted that in policies related to gender and reproductive health, the impact of climate change is not considered except for the National women development policy (2011) as discussed above.

Although women are included in adaptation discourse, genderspecific considerations are apparently not promoted. Multi-sectoral responses and collaborations to address climate change, and policies relating to disaster preparedness and response, livelihoods and health care may consider integrating gender issues into priorities (Shabib and Khan 2014). Also generalization of women is another major gap in both national and international policy papers. While most of the literatures feature women as being victims of climate change, ignore their role as active contributors to adaptation strategies in changing

Policy Gaps

- Limited number of gender sensitive policies

- Gender specific vulnerabilities and needs are not being mainstreamed

- Policies lack operational planning to address the vulnerabilities

- Generalization of women

- Ignore the roles of women as active contributors to adaptation and mitigation strategies

- Policy objectives related to climate change and gender are generally addressed as mutually exclusive issues

- Lack of gender disaggregated data environmental realities. Both the design and implementation of emerging adaptation activities must ensure participation of women.

\section{Recommendations/Future Equitable Adaptive Strategies}

The safety and security of children, elderly people and people with special needs during the disaster and postdisaster period mostly depend on women. Hence, adaptation strategies need to bolster women's capacities, power, and social resilience. Moreover, there is a need for engagement of both women and men from a gender perspective in development and implementation of climate change related development projects.

\section{STRENGTHENING ADAPTIVE CAPACITY}

- Strengthen women's experiences, knowledge and coping capacity in adaptation policies

- Promote women's direct involvement in both policy and project planning in NAPA preparation.

- Facilitate training to women's organizations, networks and support groups and opportunities to share experiences

- Adapting agricultural practices: switching to other crops; drought and salt tolerant crops; shifting cropping seasons; climate smart agriculture; integrated agriculture-aquaculture 
(fish) farming; culture of fish tolerant to higher temperature, salinity and low quality water

- To promote water saving practices

- Rainwater harvesting

- Purchasing water from water vendor

- Empower women and facilitate equal participation in management of water resources

\section{CAPACITY BUILDING AND NETWORKING}

- Capacity building (skills, knowledge, competencies) of women on agriculture and fisheries extension

- Capacity building of women in water management and water quality monitoring

- Capacity building of women in natural resource management (afforestation, reforestation, biodiversity conservation)

\section{HEALTH FACILITIES}

- Access to health facilities and services for women

- Increase in caring tasks and other preventive or alternative methods

- Strengthening health systems to respond to the health requirements of ageing populations

- Capacity building of women on emerging health issues relevant to climate change

\section{FINANCING SECURITY/SUPPORT}

- Ensure women's engagement in adaptation financing mechanisms

- Provide finance mechanisms that support alternative livelihood adaptation priorities of poor women

- Provide finance for climate change adaptation of elderly persons for development aid.

- Provide financial support to older farmers in crop diversification, livestock, land retention and land use.

\section{DISASTER PREPAREDNESS}

- Well equipped shelters for both women and men. Shelters should be designed to ensure women's needs specially privacy, safety and sanitation facilities.

- To prioritize women's social, economic, physical and psychological vulnerabilities in community-based preparedness and response plans in order to reduce the impact of disasters on women.

- women's engagement in developing the designs of shelters

- Improving homes and houses; hazard friendly structures to avoid loss and damages.

- Disaster preparedness, including training on gender sensitive disaster risk reduction

- Gender sensitive early warning systems to ensure that women are aware of the warnings and can 
- Bolstering women's participation in policy and programme cycles

- Role of elderly people should be included in disaster risk reduction and climate change adaptation and capacity-building programmes.

\section{PROGRAMS FOR CHILDREN}

- Child-focused national policy for disaster management

- Strengthening schools for local hazards, using child-focused theatre, comic books and other visual media to explain the causes and effects of disaster

- Climate change risk, age-appropriate participation of children and young people in local projects to build resilience.

Further research is needed into women's and men's different access to resources and decision making, to inform policymakers and ensure that programmes are both more efficient and relevant. Gender-sensitive research is needed to better understand the impacts of climate change in general and extreme events in particular for the vulnerable groups. There is an urgent need to collect, analyze and report relevant data disaggregated by age and sex; depending on the context should be included to enable thorough gender analysis. To gain a clearer understanding of the social, economic and cultural reasons behind particular impacts and to identify solutions that will benefit women and men along with elderly people and children experiencing these impacts, far more detailed qualitative work is needed.

\section{Reference}

Ahmed, A. F. (2010). Community-based adaptation to climate change in Bangladesh: the global initiative at local level. Monash University Sustainability Institute.

Bartlett, S. (2008). Climate Change and Urban Children: Impacts and Implicationsfor Adaptation in Low and Middle Income Countries. IIED.

Brooks, N. (2003). Vulnerability, risk and adaptation: A conceptual framework. Tyndall Centre for Climate Change Research Working Paper, 38,1-16.

Canadian International Development Association (CIDA),. (undated). Gender Equality and ClimateChange: Why consider gender equality when taking action on climate change?

CARE Bangladesh. (2009). Climate Vulnerability and Capacity Analysis.

Department for International Development (DFID),. (2007). Gender Equality Action Plan, 2007-2009.

FAO. (2011). GENDER AND CLIMATE CHANGE RESEARCH INAGRICULTURE AND FOOD SECURITY FOR RURAL DEVELOPMENT. FAO.

Field, C. B. (2012). Managing the risks of extreme events and disasters to advance climate change adaptation: special report of the intergovernmental panel on climate change. Cambridge University Press.

Hemmati, M. (2005). Gender \& Climate Change in the North: Issues, Entry Points and Strategies for the Post2012 Process and Beyond. Berlin.

Intergovernmental Panel on Climate Change (IPCC). (2007). 'Climate Change: Impacts,Adaptation and Vulnerability.

IPCC. (2014). Climate Change 2014:impacts, adaptation, and vulnerability. Vol. 1. IPCC.

McLean, K. G. (2009). Advance Guard: Climate change impacts, adaptation, mitigation and indigenous peoples. Darwin: UNU-IAS Traditional Knowledge Initiative.

Röhr, U. (2008). Gender aspects of Climate Induced Conflicts', in Environment and Conflict. Adelphi Research. World Bank. (2000). Bangladesh Climate Change and Sustainable Development. Rural Development Unit, South Asia Region. 